\title{
Co-occurrence of RNA viruses in Tasmanian-introduced bumble bees (Bombus terrestris) and honey bees (Apis mellifera)
}

\author{
Elisabeth Fung ${ }^{1}$, Kelly Hill ${ }^{2}$, Katja Hogendoorn ${ }^{1}$, Andrew B. Hingston ${ }^{3}$, \\ Richard V. GLATz ${ }^{1,4,5}$

\footnotetext{
${ }^{1}$ School of Agriculture, Food and Wine, The University of Adelaide, Adelaide, South Australia 5064, Australia

${ }^{2}$ South Australian Research and Development Institute (SARDI), Adelaide, South Australia 5001, Australia

${ }^{3}$ School of Land and Food, University of Tasmania, Private Bag 78, Hobart, Tasmania 7001, Australia

${ }^{4}$ D’Estrees Entomology \& Science Services, MacGillivray, South Australia 5223, Australia
} \\ ${ }^{5}$ South Australian Museum, Terrestrial Invertebrates, Adelaide, South Australia 5000, Australia
}

Received 22 May 2017 - Revised 12 August 2017 - Accepted 26 September 2017

\begin{abstract}
A number of bee RNA viruses, including Deformed wing virus (DWV), are so far unreported from Australia. These viruses can be introduced together with imported live honey bees (Apis mellifera) and their products, with other bee species, and bee parasites. Given that bee viruses have a profound impact on bee health, it is surprising that since the introduction of bumble bees (Bombus terrestris) onto Tasmania in 1992 from New Zealand, no work has been done to investigate which RNA viruses are associated with these bees. Consequently, we investigate the current prevalence of RNA viruses in B. terrestris and A. mellifera collected in south-eastern Tasmania. We did not find DWV in either A. mellifera and B. terrestris . However, both bee species shared Kashmir bee virus (KBV) and Sacbrood virus (SBV), but Black queen cell virus (BQCV) was detected only in A. mellifera . This reinforces the importance of ongoing strong regulation of the anthropogenic movement of live bees and their products.
\end{abstract}

\section{Apis mellifera / Bombus terrestris / RNA viruses / Tasmania / Australia}

\section{INTRODUCTION}

Over the last decade, RNA viruses of bees have received increasing attention due to their putative association with Colony Collapse Disorder (CCD), and as one of the causes of reduced health and size of populations of European honey bee (Apis mellifera L.; vanEngelsdorp et al. 2009; Neumann and Carreck 2010). RNA viruses were

Electronic supplementary material The online version of this article (https://doi.org/10.1007/s13592-017-0549-8) contains supplementary material, which is available to authorized users.

Corresponding author: E. Fung, elisabeth.fung@adelaide.edu.au Manuscript editor: Peter Rosenkranz initially called 'honey bee viruses' and described as being specific to A. mellifera (Ball and Bailey 1991). However, recent studies demonstrate their presence in many species of pollinators including bees of the genus Bombus (Singh et al. 2010; Levitt et al. 2013) with suggested ongoing exchange between species (McMahon et al. 2015; Radzeviciute et al. 2017).

Observations and experiments have suggested that bumble bees can acquire virus from wild or managed A. mellifera (McMahon et al. 2015), and from managed Bombus spp. (Graystock et al. 2014). Such inter-species horizontal transmission is strongly linked to co-foraging (i.e. foraging on the same flowers; Singh et al. 2010; Mazzei et al. 2014). For instance, under controlled conditions, Israel acute paralysis virus (IAPV) was transmitted 
between A. mellifera and B. impatiens Cresson through co-foraging (Singh et al. 2010).

Horizontal transmission can also occur via other invertebrate vectors. For instance, the Varroa mite (Varroa destructor Anderson \& Trueman) facilitates intra-species transmission between bees of the genus Apis from which they suck haemolymph. However, $V$. destructor is not directly responsible for inter-species transmission of viruses between Apis and non-Apis bees, and among non-Apis bees (Manley et al. 2015). Nonetheless, the presence of $V$. destructor in honey bee populations increases the likelihood that bumble bees and other native pollinators encounter pathogens on flowers, because the mite increases the incidence and severity of RNA viruses in hives (Brown and Fries 2007; vanEngelsdorp and Meixner 2010). Varroosis of A. mellifera leads to an increase in prevalence and titres of different RNA viruses including DWV (Mondet et al. 2014). Indeed, interaction between the $V$. destructor and DWV has been hypothesised as the greatest threat to the health of A. mellifera and the main contributor of A. mellifera colony collapse (Martin et al. 2012; Mondet et al. 2014). Contrary to claims by Wilfert et al. (2016; see discussion), it is clear that both DWV and the Varroa mite are absent from Australia (Rosenkranz et al. 2010; Roberts et al. 2015).

The spread of these and other diseases and their vectors is mainly caused by global transportation of A. mellifera and Bombus spp. for commercial use as pollinators (Manley et al. 2015; Wilfert et al. 2016). Goulson and Hughes (2015) emphasise that commercial trade of Bombus spp. is redistributing pathogens and parasites of bees into new areas around the world. This risk is increased by the fact that commercially reared Bombus spp. can carry RNA viruses probably acquired from A. mellifera pollen used for their rearing (Goulson and Hughes 2015; Graystock et al. 2016).

The bumble bee $B$. terrestris L. was first discovered in the Australian island state of Tasmania in 1992 (Semmens et al. 1993), and 9 years later it had become established in most regions of the island including remote areas (Hingston et al. 2002). The bees were accidentally or intentionally introduced from New Zealand (NZ) without the approval of the Australian government (Semmens et al. 1993). The recent detection of DWV in A. mellifera from NZ (Mondet et al. 2014) raised fears that new RNA viruses, mainly DWV could have been introduced into Tasmania with $B$. terrestris . Before introduction of B. terrestris in 1992, only Sacbrood virus (SBV) and Chronic bee paralysis virus (CBPV) were reported in Tasmanian honey bees (Hornitzky et al. 1990). In A. mellifera on mainland Australia, Black queen cell virus (BQCV), Kashmir bee virus (KBV), Cloudy wing virus (CWV), CBPV, and SBV were detected and reported in different studies (e.g. Hornitzky 1987; Anderson and Gibbs 1988).

Here, we investigate (i) which RNA viruses are present in Tasmanian B. terrestris, (ii) which viruses are shared between Tasmanian $B$. terrestris and $A$. mellifera, and (iii) the possible geographic origin of RNA viruses found in B. terrestris .

\section{MATERIALS AND METHODS}

\subsection{Sample collection}

A total of 200 foraging bees (100 B. terrestris and $100 \mathrm{~A}$. mellifera) were collected between January and February of 2015 across southeast Tasmania (Figure 1). This region was chosen because $B$. terrestris is commonly found throughout, and because it includes the capital city of Hobart where $B$. terrestris was first found (Hingston et al. 2002). Of the 100 B. terrestris, 29 were queens and 71 were workers. For A. mellifera, only workers were collected. The bees were collected from flowers at 15 sites on the main island of Tasmania, and at five sites on Bruny Island. The sites were separated by at least $2 \mathrm{~km}$. Workers of B. terrestris normally do not forage further than $1 \mathrm{~km}$ away from their nests (Osborne et al. 1999), and their maximum flight distance is $2.5 \mathrm{~km}$ (Hagen et al. 2011). Therefore, we expected that $B$. terrestris collected at different sites, originated from different colonies. On the other hand, A. mellifera can forage close to but also at distances of more than $10 \mathrm{~km}$ from their hive (Beekman and Ratnieks 2000). We consider $B$. terrestris flight distance instead of $A$. mellifera because it was our main object of study. 

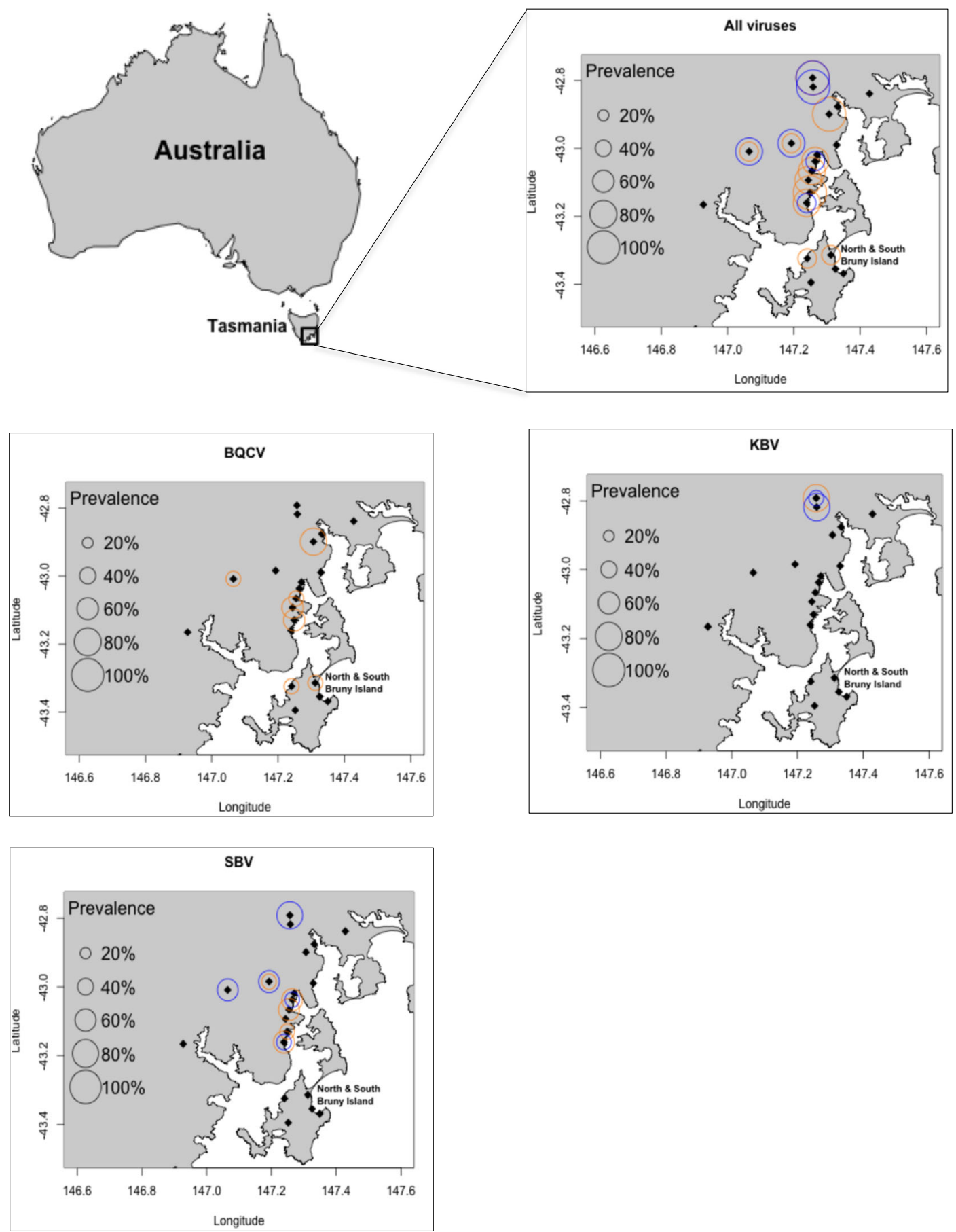

Figure 1. Prevalence (\%) and geographical distribution of combined viruses as single response, BQCV, KBV, and SBV. Black diamonds represent collection sites. Blue and orange circles represent virus detection in Bombus terrestris and Apis mellifera, respectively. Sizes of circles correspond to prevalence (\%) of the viruses. Prevalence of all viruses include a purple circle, which results from combination of blue and orange circles of the same size. 
At each site, five specimens per species were captured individually with a net while foraging on flowers of the same plant or on adjacent plants of the same species. Specimens were stored on ice while in the field. After, they were individually immersed in aliquots of RNALater and stored at $-80^{\circ} \mathrm{C}$ until shipment to Waite Research Institute, Adelaide, South Australia, for processing.

\subsection{Viral RNA extraction}

Prior to extraction, bees were washed with $1 \%$ sodium dodecyl sulphate to remove pollen from their bodies and other possible contaminants. Total RNA was extracted using a GenElute Mammalian Total RNA Miniprep Kit (Sigma-Aldrich) following the manufacturer's protocol. Any DNA contamination was removed from the RNA preparations using On-Column DNase I Digestion (Sigma-Aldrich). The purity of the total RNA was measured using a NanoDrop ND-1000 spectrophotometer (Thermo Fisher Scientific), and the concentration was measured using a Qubit ${ }^{\circledR}$ 3.0 Fluorometer (Thermo Fisher Scientific). RNA samples were stored at $-80^{\circ} \mathrm{C}$ until used.

\subsection{Virus detection}

We aimed to determine the presence of eight RNA viruses, namely Acute bee paralysis virus (ABPV), BQCV, CBPV, DWV, IAPV, KBV, SBV, and Slow bee paralysis virus (SBPV). To achieve this, $0.5-5 \mu \mathrm{g}$ of total RNA was reverse transcribed using random hexamers (Bioline) and a Bioscript reverse transcriptase kit (Bioline) according to the manufacturer's guidelines. Two microliter of RT reaction contents were added to a final $25 \mu \mathrm{L}$ PCR solution, with amplification occurring under the following conditions: initial denaturation for $5 \mathrm{~min}$ at $94^{\circ} \mathrm{C}, 35$ cycles of denaturation for $30 \mathrm{~s}$ at $94^{\circ} \mathrm{C}, 30 \mathrm{~s}$ annealing at $55^{\circ} \mathrm{C}, 90 \mathrm{~s}$ extension at $72^{\circ} \mathrm{C}$, and a final extension for $5 \mathrm{~min}$ at $72^{\circ} \mathrm{C}$. PCR products were visualised under UV light on $1 \%$ agarose gels stained with GelGreen Nucleic Acid Gel Stain (Biotium). No-template, internal, and positive controls were included in each group of RT-PCR reactions. The internal control used in this study amplifies the D2 region of 28S ribosomal DNA (Campbell et al. 2000). This was used as housekeeping gene to control for the quality of the RNA extracted from bees and the correct application of each batch of RT-PCRs. All primers used in this study are listed in Online Resource -ESM1. Positive samples were confirmed by sequencing of PCR products.

\subsection{Sequence and phylogenetic analyses}

PCR products were purified using the UltraClean PCR Clean-Up Kit (MOBIO Laboratories, Inc.) and sent for bidirectional Sanger sequencing. Sequences were then matched against those in the National Center for Biotechnology Information (NCBI) and used for phylogenetic analysis. Detailed methodology of phylogenetic analyses can be found in Online Resource-ESM2.

\subsection{Statistical analysis}

All statistical analyses were executed in $\mathrm{R}$ version 3.2.1 (R Core Team, 2016). The prevalence of all RNA viruses and $95 \%$ confidence intervals were calculated for both bee species using the function epi.prev ( $\mathrm{R}$ library 'epiR' package version 0.9-62). Prevalence of RNA viruses was mapped according to the collection sites using the 'Mapplots' package version 1.5. Fisher's exact test was used to infer any relationship between the proportions of infected A. mellifera and B. terrestris.

Spatial autocorrelation of the prevalence of SBV and BQCV for A. mellifera and SBV for $B$. terrestris from all locations was computed using Moran's I test (R library 'ape' package version 3.3) to assess disease hotspots and spatial patterns. Spatial autocorrelation of KBV was not determined because of the low prevalence $(n<5)$ in both $B$. terrestris and A. mellifera . Moran's I is an indicator of spatial clustering, and in this case, it was used to assess whether presence of RNA viruses in one location was influenced by the presence of the same viruses in adjacent sites (spatial clustering; Fürst et al. 2014).

In order to investigate the impact of the prevalence of SBV in A. mellifera on SBV in $B$. terrestris, we ran a generalised linear model 
(GLM) with binomial error and logit link (glm function from R library 'stats' package version 3.2.1). The other viruses detected, BQCV and $\mathrm{KBV}$, were not modelled because of absence of $\mathrm{BQCV}$ in $B$. terrestris, and low prevalence of KBV $(n<5)$ in both bee species. The best model was selected based on the Akaike Information Criterion (AIC).

\section{RESULTS}

The prevalence of RNA viruses considering all viruses as single response (i.e. assessing individuals carrying at least one RNA virus) associated with workers and queens of $B$. terrestris was $17 \%$ (95\% CI $10-27 \%)$ and $0 \%$ (95\% CI $0-12 \%)$, respectively, but this difference was not statistically significant $(P=0.41)$. For this reason, we treated both workers and queens of $B$. terrestris as the same for the following analyses. The overall prevalence of RNA viruses associated with A. mellifera was higher than in B. terrestris (Table I). The majority of viruses occurred as a single infection in individual bees, but detection of coinfections occurred for both A. mellifera and $B$. terrestris . KBV and SBV were detected in both $B$. terrestris and A. mellifera (Table I; Figure 1) and the prevalence did not differ between bee species (KBV: $P=1$; SBV: $P=0.21$ ). BQCV was detected only in A. mellifera (Table I; Figure 1) and its higher prevalence was statistically significant $(P=0.0003)$. It was also the most prevalent virus in A. mellifera (Table I). None of the $B$. terrestris or A. mellifera individuals testing positive to RNA virus showed obvious symptoms of virus infection. ABPV, CBPV, DWV, IAPV, and SBPV were not detected in our samples.

No evidence of spatial clustering was found for $\operatorname{BQCV}(P=0.84)$ and $\operatorname{SBV}(P=0.17)$ in A. mellifera . Similarly, for $B$. terrestris, no spatial clustering was detected for SBV $(P=0.99)$ and latitude and longitude did not influence its prevalence (Table II). Mapping the prevalence of all RNA viruses as single response, in order to avoid underestimation of disease prevalence, suggested that prevalence of RNA viruses in B. terrestris and $A$. mellifera was associated (Figure 1). The prevalence of SBV in $B$. terrestris was positively associated with its occurrence in A. mellifera (Table II) and vice versa (Online Resource -ESM3).

The KBV and SBV sequences from $B$. terrestris and A. mellifera from Tasmania clustered together, distinct from A. mellifera sequences from other countries (Online Resources -ESM4 and 5). The BQCV sequence from A. mellifera from Tasmania clustered with a sequence from UK (Online Resource -ESM6), in agreement with historical reports of Europe as source of A. mellifera imported to Australia (Hopkins 1886; Glatz 2015). The KBV sequences from Tasmania and other countries clustered together, and separately from IAPV sequences (Online Resource -ESM4).

\section{DISCUSSION AND CONCLUSIONS}

We found that $B$. terrestris and A. mellifera in Tasmania have two RNA viruses in common: $\mathrm{KBV}$ and SBV, while BQCV was detected only in A. mellifera. Although our results suggest BQCV to be less amenable to inter-species transmission through co-foraging than $\mathrm{SBV}$, it is known that BQCV can infect different Bombus spp. including B. terrestris (Peng et al. 2011; Radzeviciute et al. 2017) possibly through ingestion of virus contamination, a common pathway of intra- and inter-species transmission of RNA viruses. BQCV and SBV were also detected during a recent survey of RNA viruses in Australian A. mellifera in Tasmania (Roberts et al. 2015). Our data confirm previous studies that have shown susceptibility of $B$. terrestris to SBV infection (Singh et al. 2010; Levitt et al. 2013).

Our findings suggest that indirect transmission of KBV and SBV by co-foraging might have occurred between $B$. terrestris and A. mellifera in Tasmania. This is supported by the result that prevalence of SBV in A. mellifera was a good predictor of prevalence of the same virus in $B$. terrestris, and vice versa as well as by the result that both species appeared to carry the same strains of these two viruses in Tasmania, which where distinct from viral sequences obtained for both species in other regions. Similar local sharing of viruses between $A$. mellifera and $B$. terrestris has been found for DWV (Fürst et al. 2014; McMahon et al. 2015; Radzeviciute et al. 2017). 
Table I. Prevalence (\%) of RNA viruses in Bombus terrestris $(n=100)$ and Apis mellifera $(n=100)$ with $95 \%$ confidence interval in square brackets. ABPV, CBPV, DWV, IAPV, and SBPV were not detected in either species.

\begin{tabular}{llllll}
\hline Species of bee & BQCV & KBV & SBV & Overall & $P$ value \\
\hline A. mellifera & $11[6-19]$ & $3[1-8]$ & $9[5-16]$ & $21[14-30]$ & $0.04^{*}$ \\
B. terrestris & - & $4[2-9]$ & $9[5-16]$ & $12[7-20]$ & \\
\hline
\end{tabular}

Viral transfer between these species is likely to be brought about through co-foraging because they are both polylectic and forage on a wide variety of native and introduced plants in Tasmania (Hingston 2005), often using the same plant species as food sources (Hingston and McQuillan 1998). At the time of collection, these species had been foraging together in Tasmania for 23 years (Semmens et al. 1993).

It seems likely that BQCV, KBV, and SBV were introduced into Tasmania with A. mellifera, as they are also found on the mainland of Australia. Moreover, on the basis of our data, we cannot exclude introduction with $B$. terrestris. For BQCV, introduction with A. mellifera is likely, as we did not detect it in $B$. terrestris, despite the fact that it has been reported in Bombus spp. elsewhere (Singh et al. 2010; Levitt et al. 2013). Whether B. terrestris introduced into Tasmania were carrying SBV and $\mathrm{KBV}$, or whether they became infected after arrival or both remains unclear. Because SBV was reported in the island before the introduction of B. terrestris (Hornitzky et al. 1990), it likely was introduced with $A$. mellifera. However, because SBV and KBV were both present in A. mellifera from NZ before introduction of $B$. terrestris into Tasmania (Anderson 1985), the possibility of virus introduction onto Tasmania via NZ-derived
B. terrestris remains open. KBV was detected in Australian mainland A. mellifera after their introduction into Tasmania (Anderson and Gibbs 1988; Anderson 1991) and the data are therefore inconclusive. Therefore, we are cautious in postulating the origin or the original host of all viruses we detected, and we cannot discard the possibility that other native bees or insects could have been the primary host of the viruses. The RNA viruses found by us have also been detected in solitary bees and other Hymenoptera such as wasps and ants, as well as non-hymenopteran insects such as butterflies, beetles, and flies (Singh et al. 2010; Levitt et al. 2013).

Interestingly, for the first time in Tasmania, $\mathrm{KBV}$ was detected at very low prevalence in both A. mellifera and B. terrestris. The other recent survey of RNA viruses did not detect KBV in Tasmania, although it detected IAPV in Tasmania and the Australian mainland (Roberts et al. 2015).

The phylogenetic tree generated from KBV and IAPV sequences from Tasmania and other countries showed that they are distinct since these viruses clustered separately. Literature and public sequence databases continue to misclassify IAPV and KBV although they are classified as different virus species by the International Committee on Taxonomy of Viruses (King et al. 2012). Phylogenetic analysis of IAPV and KBV RNA-

Table II. Generalised Linear Models parameter values for the best model explaining prevalence of SBV in $B$. terrestris using lowest AIC value for model selection.

\begin{tabular}{|c|c|c|c|c|c|c|}
\hline Response & Virus & Parameters & Estimate & $\mathrm{SE}$ & $z$ value & $P$ value \\
\hline \multirow{4}{*}{$\begin{array}{l}\text { B. terrestris } \\
\text { virus prevalence }\end{array}$} & \multirow[t]{4}{*}{ SBV } & Intercept & -278.99 & 674.63 & -0.41 & 0.68 \\
\hline & & Apis SBV & 2.52 & 1.01 & 2.5 & $0.01 *$ \\
\hline & & Latitude & -1.66 & 2.24 & -0.74 & 0.46 \\
\hline & & Longitude & 1.39 & 4.49 & 0.31 & 0.76 \\
\hline
\end{tabular}


dependent RNA polymerase sequences suggest that some IAPV isolates from Australia, France, and Russia may have been incorrectly classified as KBV in earlier studies (Palacios et al. 2008; de Miranda et al. 2010). This emphasises problems with online sequence databases and molecular virus diagnostics (de Miranda et al. 2010), particularly with regard to design of specific diagnostic primers.

Importantly, we did not detect bees carrying ABPV, CBPV, DWV, IAPV, and SBPV. ABPV and SBPV have not been reported in Australia before (Allen and Ball 1996; Roberts et al. 2015); therefore, our data, although limited, support that Australia remains free of these viruses. Similarly to our results, CBPV was not detected during the most recent survey of RNA viruses of hived Australian A. mellifera (Roberts et al. 2015). We cannot exclude the possibility of occurrence of different RNA virus variants that did not amplify with the set of primers we employed. Further research is required with a larger sample size of $B$. terrestris and using deep sequencing to allow detection of all virus variants and novel viruses.

Contrary to a recent report (Singh et al. 2010; Wilfert et al. 2016), our results together with those of Roberts and Anderson (2013) and Roberts et al. (2015) suggest the absence of DWV in Australia. Roberts et al. (2015), who did not detect DWV, performed a very extensive survey of managed hives around Australia and they used very sensitive techniques for detection of viruses (deep sequencing). Hence, it is hard to reconcile the detection of DWV in a small sample of A. mellifera imported from Australia with the lack of detection in a large number of recently tested A. mellifera. Intriguingly, Roberts et al. (2015) reported a small number of short nucleic acid sequences with 77$92 \%$ similarity to DWV; these were considered to be different viruses but closely related to DWV. DWV occurs as two main variants, genotype A (conventional) and genotype $\mathrm{B}$, which is closely related to Varroa destructor virus (VDV-1) and around $82 \%$ identical to conventional DWV (Ongus et al. 2004; Martin et al. 2012). Therefore, we cannot eliminate the risk of occurrence of DWV genotype B, although Roberts et al. (2015) reported short nucleic acid sequences
$78 \%$ similar to VDV-1. Indeed, the presence and variability of DWV-like sequences in Australian bees need further research in order to unambiguously define DWV status in Australia. At present, we consider IAPV but not DWV to be present in Australia.

Our study highlights the importance of stringent policy measures to restrict anthropogenic movement of bees and associated products in order to prevent introduction of $V$. destructor and DWV in Australia, as we consider this virus to be absent. The combination of both $V$. destructor and DWV causes serious harm to the health of A. mellifera, whether introduced simultaneously or separately. In New Zealand, while DWV and $V$. destructor were introduced separately (Zhang 2000; Mondet et al. 2014), the impact of combination of both in A. mellifera colony losses was significant (Mondet et al. 2014). Therefore, it is important to consider separate as well as simultaneous introduction of DWV and $V$. destructor. Manley et al. (2015) highlight the importance of maintaining the few current Varroa-free areas free of $V$. destructor. Importation of live bees including A. mellifera and Bombus spp., and honey bee products such as semen, pollen, and royal jelly should be restricted and extremely diligently monitored to avoid introduction of DWV into Australia. In addition, measures to avoid the independent introduction of the Varroa mite or of associated viruses should be explored. Such measures include prioritisation of the use of native bees for pollination, reduction, or cessation of the importation of non-native bees, and monitoring the prevalence of RNA viruses in native bees to allow early detection of disease-associated decline in populations (Goulson and Hughes 2015).

\section{ACKNOWLEDGEMENTS}

We thank the Holsworth Wildlife Research Endowment-Equity Trustees for their continued and generous financial support, which was essential for molecular analysis of our samples. We thank Stephen Pederson (The University of Adelaide) for his help in using $\mathrm{R}$. We are grateful to the anonymous reviewers for constructive suggestions that improved substantially the manuscript. 


\section{AUTHOR CONTRIBUTIONS}

EF: designed and performed experiment and data analyses, and wrote the paper. $\mathrm{KH}, \mathrm{KH}, \mathrm{RG}$ : experiment design, technical assistance, and edition of the paper. AH: sample collection and edition of the paper. All authors read and approved the final manuscript.

Virus à ARN présents dans des bourdons (Bombus terrestris) et des abeilles (Apis mellifera) introduits en Tasmanie

\section{Apis mellifera / Bombus terrestris / introduction de col- onies / virus/ Australia}

Gemeinsames Auftreten von RNA-Viren in nach Tasmanien eingeführten Hummeln (Bombus terrestris) und Honigbienen (Apis mellifera)

\section{Apis mellifera / Bombus terrestris / RNA viruses / Tasma- nia / Australia}

\section{REFERENCES}

Allen M., B. Ball. (1996) The incidence and world distribution of honey bee viruses. Bee World 77 (3): 141162.

Anderson D. (1985) Viruses of New Zealand honey bees. New Zealand Beekeeper (188): 8-10.

Anderson D.L. (1991) Kashmir bee virus - a relatively harmless virus of honey-bee colonies. Am. Bee J. 131 (12): 767-770.

Anderson D.L., A.J. Gibbs. (1988) Inapparent virusinfections and their interactions in pupae of the honey bee (Apis mellifera Linnaeus) in Australia. J. Gen. Virol. 69: 1617-1625.

Ball B., L. Bailey. (1991) Viruses of honey bees, in: Adams J.R. and Bonami J.R. (Eds.), Atlas of invertebrate viruses, CRC Press, Inc., Boca Raton, pp. 525-551.

Beekman M., F.L.W. Ratnieks. (2000) Long-range foraging by the honey-bee, Apis mellifera L. Funct. Ecol. 14 (4): 490-496.

Brown M.J.F., I. Fries. (2007) Evolutionary epidemiology of virus infections in honey bees, in: Aubert M., Ball B., Fries I., Moritz R., Milani N., and Bernardinelli I. (Eds.), Virology and the honey bee, European Communites, Belgium pp. 279-306.

Campbell B., J. Heraty, J.Y. Rasplus, K. Chan, J. SteffenCampbell, et al. (2000) Molecular systematics of the
Chalcidoidea using 28S-D2 rDNA, in: Austin A.D. and Dowton M. (Eds.), Hymenoptera: evolution, biodiversity and biological control., CSIRO, Collingwood, pp. 59-73.

de Miranda J.R., G. Cordoni, G. Budge. (2010) The Acute bee paralysis virus-Kashmir bee virus-Israeli acute paralysis virus complex. J. Invertebr. Pathol. 103 : S30-S47.

Fürst M.A., D.P. McMahon, J.L. Osborne, R.J. Paxton, M.J.F. Brown. (2014) Disease associations between honeybees and bumblebees as a threat to wild pollinators. Nature 506 (7488): 364-366.

Glatz R.V. (2015) Curious case of the Kangaroo Island honeybee Apis mellifera Linnaeus, 1758 (Hymenoptera: Apidae) sanctuary. Austral Entomol. 54 (2): 117126.

Goulson D., W.O.H. Hughes. (2015) Mitigating the anthropogenic spread of bee parasites to protect wild pollinators. Biol. Conserv. 191 : 10-19.

Graystock P., D. Goulson, W.O.H. Hughes. (2014) The relationship between managed bees and the prevalence of parasites in bumblebees. Peerj 2 . e522.

Graystock P., J.C. Jones, T. Pamminger, J.F. Parkinson, V. Norman, et al. (2016) Hygienic food to reduce pathogen risk to bumblebees. J. Invertebr. Pathol. 136 : 6873.

Hagen M., Wikelski, M., Kissling, W.D. (2011) Space Use of Bumblebees (Bombus spp.) Revealed by RadioTracking. Plos One 6(5).

Hingston A.B. (2005) Does the introduced bumblebee, Bombus terrestris (Apidae), prefer flowers of introduced or native plants in Australia? Aust. J. Zool. 53 (1): 29-34.

Hingston A.B., J. Marsden-Smedley, D.A. Driscoll, S. Corbett, J. Fenton, et al. (2002) Extent of invasion of Tasmanian native vegetation by the exotic bumblebee Bombus terrestris (Apoidea : Apidae). Austral Ecol. 27(2): 162-172.

Hingston A.B., P.B. McQuillan. (1998) Does the recently introduced bumblebee Bombus terrestris (Apidae) threaten Australian ecosystems? Aust. J. Ecol. 23 (6): 539-549.

Hopkins I. (1886) The illustrated Australasian bee manual and complete guide to modern bee culture in the southern hemisphere. H. H. Hayr \& Co., Agents Auckland.

Hornitzky M., R. McDonald, G. Kleinschmidt. (1990) Commercial beekeeping in Tasmania. Honey Research Council, Kingston.

Hornitzky M.A. (1987) Prevalence of virus-infections of honeybees in Eastern Australia. J. Apic. Res. 26 (3): 181-185.

King A., M. Adams, E. Carstens, E. Lefkowitz. (2012) Virus taxonomy - Ninth report of the International Committee on Taxonomy of Viruses. Elsevier Inc., San Diego.

Levitt A.L., R. Singh, D.L. Cox-Foster, E.G. Rajotte, K. Hoover, et al. (2013) Cross-species transmission of 
honey bee viruses in associated arthropods. Virus Res. 176 (1-2): 232-240.

Manley R., M. Boots, L. Wilfert. (2015) Emerging viral disease risk to pollinating insects: ecological, evolutionary and anthropogenic factors. J. Appl. Ecol. 52 (2): 331-340.

Martin S.J., A.C. Highfield, L. Brettell, E.M. Villalobos, G.E. Budge, et al. (2012) Global honey bee viral landscape altered by a parasitic mite. Science 336 (6086): 1304-1306.

Mazzei M., Carrozza, M.L., Luisi, E., Forzan, M., Giusti, M., et al. (2014) Infectivity of DWV associated to flower pollen: experimental evidence of a horizontal transmission route. Plos One 9 (11).

McMahon D.P., M.A. Fürst, J. Caspar, P. Theodorou, M.J.F. Brown, et al. (2015) A sting in the spit: widespread cross-infection of multiple RNA viruses across wild and managed bees. J. Anim. Ecol. 84 (3): 615-624.

Mondet F., de Miranda, J.R., Kretzschmar, A., Le Conte, Y., Mercer, A.R. (2014) On the front line: quantitative virus dynamics in honeybee (Apis mellifera L.) colonies along a new expansion front of the parasite Varroa destructor. PLoS Pathog. 10 (8).

Neumann P., N.L. Carreck. (2010) Honey bee colony losses. J. Apic. Res. 49 (1): 1-6.

Ongus J.R., D. Peters, J.M. Bonmatin, E. Bengsch, J.M. Vlak, et al. (2004) Complete sequence of a picorna-like virus of the genus Iflavirus replicating in the mite Varroa destructor. J. Gen. Virol. 85 : 3747-3755.

Osborne J.L., S.J. Clark, R.J. Morris, I.H. Williams, J.R. Riley, et al. (1999) A landscape-scale study of bumblebee foraging range and constancy, using harmonic radar. J. Appl. Ecol. 36(4): 519-533.

Palacios G., J. Hui, P.L. Quan, A. Kalkstein, K.S. Honkavuori, et al. (2008) Genetic analysis of Israel acute paralysis virus: distinct clusters are circulating in the United States. J. Virol. 82 (13): 6209-6217.

Peng W.J., J. Li, H. Boncristiani, J.P. Strange, M. Hamilton, et al. (2011) Host range expansion of honeybee Black queen cell virus in the bumblebee, Bombus huntii. Apidologie 42 (5): 650-658.
R Core Team (2016) R: A language and environment for statistical computing, R Foundation for Statistical Computing, Vienna.

Radzeviciute R., P. Theodorou, M. Husemann, G. Japoshvili, G. Kirkitadze, et al. (2017) Replication of honey bee-associated RNA viruses across multiple bee species in apple orchards of Georgia, Germany and Kyrgyzstan. J. Invertebr. Pathol. 146 : 14-23.

Roberts J., D. Anderson. (2013) Establishing the disease status of the Asian honeybee in the Cairns region, Rural Industries Research \& Development Corporation (RIRDC) Canberra.

Roberts J., D. Anderson, P. Durr. (2015) Upgrading knowledge on pathogens (particularly viruses) of Australian honey bees, Rural Industries Research \& Development Corporation (RIRDC) Canberra

Rosenkranz P., P. Aumeier, B. Ziegelmann. (2010) Biology and control of Varroa destructor. J. Invertebr. Pathol. 103 : S96-S119.

Semmens T.D., E. Turner, R. Buttermore. (1993) Bombus terrestris (L) (Hymenoptera, Apidae) now established in Tasmania. J. Aust. Entomol. Soc. 32 : 346-346.

Singh R., A.L. Levitt, E.G. Rajotte, E.C. Holmes, N. Ostiguy, et al. (2010) RNA viruses in hymenopteran pollinators: evidence of inter-taxa virus transmission via pollen and potential impact on non-Apis hymenopteran species. PloS One 5 (12): 1-16.

vanEngelsdorp D., J.D. Evans, C. Saegerman, C. Mullin, E. Haubruge, et al. (2009) Colony collapse disorder: a descriptive study. Plos One 4 (8): e6481.

vanEngelsdorp D., M.D. Meixner. (2010) A historical review of managed honey bee populations in Europe and the United States and the factors that may affect them. J. Invertebr. Pathol. 103 : S80-S95.

Wilfert L., G. Long, H.C. Leggett, P. Schmid-Hempel, R. Butlin, et al. (2016) Deformed wing virus is a recent global epidemic in honeybees driven by Varroa mites. Science 351 (6273): 594-597.

Zhang Z.-Q. (2000) Notes on Varroa destructor (Acari: Varroidae) parasitic on honeybees in New Zealand. Syst. Appl. Acarol. Spec. Publ. 5 : 9-14. 